\title{
Editorial
}

\section{Hacia el reconocimiento e impacto internacional}

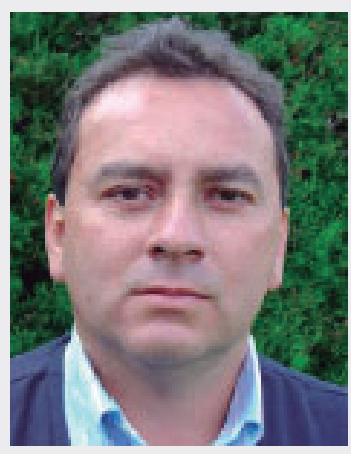

Para las directivas de la Universidad Colegio Mayor de Cundinamarca y de la Universidad Nacional Abierta y a Distancia, y de manera particular para la Escuela de Ciencias de la Salud de ambas instituciones es muy satisfactorio poner en circulación el segundo número de esta alianza estratégica, cuyo objetivo es seguir visibilizando y consolidando la Revista NOVA como una de las mejores en el campo de las Ciencias Biomédicas en Latinoamérica. Para ello no se ha escatimado ningún esfuerzo humano, técnico y científico que conlleve a NOVA a alcanzar el reconocimiento e impacto en la comunidad científica nacional e internacional de una revista de primer orden.

Además de contar en los Comités Editorial y Científico con profesionales reconocidos a nivel nacional e internacional en los campos temáticos de las Ciencias Biomédicas, especialidad de la revista, la Dirección Editorial de la Revista NOVA ha sido muy cuidadosa en la selección de los pares académicos que fungen como evaluadores, quienes han sido escogidos por su amplia trayectoria investigativa y por dirigir proyectos de alta envergadura en prestigiosas instituciones universitarias, lo cual, de alguna manera, garantiza la alta calidad de las producciones que en cada número se publican.

El número 20 de la Revista NOVA no es la excepción, y es así como en este volumen un equipo del Centro de Investigaciones Odontológicas de la Pontificia Universidad Javeriana, presenta el trabajo "Efecto del Mercurius-Heel ${ }^{\oplus}$ s sobre la citotoxicidad de fibroblastos gingivales humanos en un modelo in vitro", en el que teniendo en cuenta los resultados de esta investigación, se sugiere el uso del Mercurius Heel ${ }^{\circledR}$ como tratamiento complementario en la enfermedad periodontal, ya que no presentó ningún efecto citotóxico en el cultivo celular de fibroblastos gingivales.

En el artículo "Cultivo de la línea celular HEp-2: doblaje poblacional y coloración con Giemsa. Perspectivas para el estudio de la infección con Chlamydia trachomatis", se resalta el uso de los cultivos celulares en la investigación básica en diferentes disciplinas biológicas, y se establece la importancia de la línea celular HEp-2 (Human Epidermoid Cancer Cells) que es utilizada en estudios de infección con diferentes bacterias, entre ellas Chlamydia trachomatis con el objetivo de establecer los mecanismos por los cuales este patógeno sobrevive en la célula huésped. En este trabajo se realizaron curvas de crecimiento con medios DMEM-F12 y MEM, se estandarizó la coloración con Giemsa y se calculó el doblaje poblacional con diferentes inóculos para evaluar el desarrollo de la línea celular en cul $\neg$ tivo, y de esta manera poder elegir las condiciones óptimas para realizar futuros ensayos de infección con parásitos.

El artículo "La obesidad y su relación con otros factores de riesgo cardiovascular en una población de estudiantes universitarios del centro de Bogotá", muestra los resultados de una investigación que tuvo como propósito describir la relación existente entre la obesidad y otros de factores de riesgo cardiovas $\neg$ cular en un grupo de estudiantes universitarios del centro de Bogotá. Este trabajo es desarrollado por un equipo de la Facultad de Medicina de la Universidad de La Sabana, de Bogotá, Colombia. 
Los resultados obtenidos sugieren que es fundamental promover en los jóvenes una cultura de hábitos saludables, la cual abarca no solo alimentación saludable sino también una mayor actividad física.

También hace parte de este volumen el artículo titulado "Bacillus thuringiensis: manejo del agente de la pudrición blanda de la papa Erwinia carotovora”, en él se describe el mecanismo que emplea la bacteria Bacillus thuringiensis para suprimir la virulencia de E. caratovora, ya que produce $\mathrm{N}$-acil-homoserinalactonasa, una potente enzima que degrada de $\mathrm{N}$-acil-homoserinolactonas, los cuales son necesarios en el mecanismo de quorum-sensing de E. caratovora. Este aspecto es fundamental si se considera que en Colombia el cultivo de papa es el cuarto en importancia en la economía del país, y su producción puede alcanzar las 300 millones de toneladas anualmente.

El quinto artículo seleccionado para este número "Calidad sanitaria del agua del Parque Natural Chicaque", desarrollado por docentes del programa de bacteriología de la Universidad Colegio Mayor de Cundinamarca, tuvo por objetivo evaluar la calidad del agua del Parque Natural Chicaque, ubicado a una hora de Bogotá, Colombia. El aislamiento de Coliformes totales, Escherichia coli y Enterococcus en el agua del Parque, muestra la contaminación fecal de las aguas, lo cual, como manifiestan las autoras, indica que la presencia de estos grupos de bacterias está relacionada con el impacto de las actividades de los seres humanos y animales sobre los cuerpos de agua y el manejo de las aguas residuales.

El grupo de Calidad de Aguas del Programa de Bacteriología y Laboratorio Clínico de la Universidad Colegio Mayor de Cundinamarca, presenta los resultados de su estudio "Calidad microbiológica del agua de unidades odontológicas de una clínica universitaria de Bogotá”. Sus resultados permiten establecer que el agua destinada al uso de las unidades odontológicas no cumple, en lo referente a las características microbiológicas, con lo establecido por la Resolución 2115 del 2007, y la Norma Técnica Colombiana 813 (NTC 813), pues excede los límites aceptables para los microorganismos encontrados.

En el siguiente artículo, estudiantes del Programa Bacteriología y laboratorio clínico, y que forman parte del Semillero de Investigación Anakalipse de la Universidad Colegio Mayor de Cundinamarca, con la asesoría de una docente, desarrollaron un estudio descriptivo-longitudinal cuyo objetivo fue la valoración del "Uso de dispositivos de micronebulización en adultos mayores en un programa de hospitalización domiciliaria"; para ello tuvieron en cuenta condiciones relacio $\neg$ nadas con el dispositivo de micronebulización como: el tiempo de uso, el lavado del dispositivo y su almacenamiento. Además de los microorganismos identificados, la importancia de este estudio se centra en la necesidad de brindar información oportuna a los pacientes, familia $\neg$ res y/o cuidadores sobre el almacenamiento adecuado del dispositivo con el fin de evitar presencia de microorganismos que pueden afectar la salud de los adultos mayores.

En el último artículo producto de investigación, que las autoras denominaron "Análisis correlacional del perfil de dominancia cerebral de estudiantes de ciencias de salud y estudiantes de ciencias sociales de la Universidad Colegio Mayor de Cundinamarca", se muestran los resultados correspondientes al análisis correlacional de los perfi les de dominancia cerebral o estilos de pensamiento de los estudiantes de 
Ciencias de la Salud y Ciencias Sociales de esta institución. Las autoras toman como base el modelo de Cerebro Total de Herrmann y los estudios recientes de Omar Gardié. Plantean además que los perfiles de dominancia de los estudiantes se relacionan con las disciplinas que han seleccionado en su formación.

Como parte de los artículos de revisión, inicialmente el lector encontrará una descripción de los aspectos más importantes de Bacillus thuringiensis y su aplicación como herramienta biotecnológica en el sector agrícola. Este texto amplia y profundiza algunos aspectos presentados en el artículo que describe el uso de Bacillus thuringiensis para suprimir la virulencia de E. caratovora.

En el siguiente artículo de esta sección, los autores, de campos disciplinares distintos, pero con un interés común, exponen en su texto "Intervenciones disruptivas al comienzo de la vida humana: un debate bioético y del bioderecho sobre la 'pena de muerte' prenatal" algunas ideas fundamentales sobre la dignidad del ser humano, partiendo su reflexión desde el momento de la concepción. Los autores centran su análisis en la "pena de muerte prenatal" ante el aborto en Espańa y Colombia.

De otro lado, y teniendo en cuenta que Colombia es uno de los países latinoamericanos con mayor inequidad, lo cual, según los autores del artículo "Erradicación de la pobreza y calidad en la salud: elementos indispensables para alcanzar la cohesión social en Colombia" son la causa de las desigualdades y brechas socioeconómicas, los autores reflexionan sobre la incidencia de la pobreza como factor de riesgo en la calidad de la salud, hacen énfasis en la desnutrición, como factores que son necesarios mejorar considerablemente para empezar a pensar en cohesión social.

Finalmente, en el artículo "La gestión integral del riesgo en territorios urbanos" los autores parten de la necesidad de reconocer el problema del flujo migratorio desde el medio rural a las ciudades, lo cual genera graves problemas sociales y de organización del espacio, para luego describir los parámetros que se deben tener en cuenta para considerar a la ciudad como un socioecosistema y como alternativa que permite hacer gestión del riesgo.

Esperamos que los artículos que se presentan en este número, que son de alta calidad, contribuyan al aumento de la visibilidad, no solo de la Revista NOVA sino también de la investigación que se adelanta en las diferentes instituciones nacionales; que facilite también el acceso a la información con calidad en la Región Latinoamericana, lo cual favorece el crecimiento de las comunidades científicas en la llamada Sociedad del Conocimiento. No podemos dejar pasar esta oportunidad para recordarle a todos los lectores que la Revista NOVA está indexada en el sistema Publindex de Colciencias así como en las más importantes bases de datos de la literatura científica y técnica en salud de América Latina y el Caribe, como LILACS, REDALYC, el FARO y EBSCO.

Rubinsten Hernández Barbosa Asistente Editorial, Revista NOVA Publicación Científica en Ciencias Biomédicas Docente Investigador de la Universidad Autónoma de Colombia. MSc. en Biología, PUJ. 